\title{
The Links between Innovative Behavior and Strategic Thinking
}

\author{
Raushan Gross \\ Pfeiffer University \\ E-Mail: Raushan.gross@pfeiffer.edu
}

This research presents a frontier analysis, linking two previously separate constructs that cut across many organizational functions: innovative behavior and strategic thinking. Strategic thinking is often viewed prima facie, as a dynamic capability and is used as a competitive apparatus; the factors that influence this mode of thinking have rarely been questioned. This study advances theory by quantitatively testing the effect of innovative behavior's on strategic thinking from the organizational perspective. Data was gathered from 100 respondents and subjected to hierarchical regression analysis while controlling for age, gender, and years on the job. The final analysis suggests that innovative behavior has a positive and significant impact on the strategic thinking of individuals and groups.

Keywords: Innovative Behavior, Strategic Thinking, Management, Organizational Theory

\section{INTRODUCTION}

Innovative behavior can have both positive and negative effects on the climate, process, and structure of an organization. Some of the more familiar of these are related to co-worker stress, strategic direction, and span of control over workload, perception of management, and management support. In a business landscape with vigilant competitors and where management is charged with leading with an entrepreneurial spirt, this spirit is transmitted to employees and it affects their behaviors and thinking. If management cultivates innovative behavior, then innovative behavior might affect strategic thinking capabilities. This research uses an interactionist perspective (Janssen, 2005) to explore the interaction between ideation and employee behavior in innovative pursuits in the workplace. Therefore, this research offers a quantitative examination of the impact (or lack thereof) of innovative behavior on employees' strategic thinking. It also explicates the linkages between the 
innovative behavior and strategic thinking and whether the two are antecedents or determinants of strategic thinking.

The literature describes the dangers of innovative behavior, the risk involved in the transmutation of ideas, and outlines the personal factors related to the potential sociopolitical outcomes (Dougherty and Heller, 1994; Janssen, 2005) when innovative behavior is unleashed in a constrained organizational system. This notion is apparent in the work of Gross (2016) who implied that strategic thinking "is dependent on the firm's social system, as it is the strategic thinkers' ability to incorporate, motivate and find support within systems that can both cultivate and encourage this mode of thinking" (p. 34). Henceforth, there are structural and psychological implications to strategic thinking and innovative behavior, but conversely, the interaction of these variables has significant bearings on the outcomes of employees' behavioral decisions. Hung (2004) agreed that despite either innovative approach (social or individual) there is a constrained view of this behavior and that the social structure determines the outcomes. Through Hun's perspective, there's evidence that external to the organizational ecosystem, market demands are related to an organizations propensity to embrace and cultivate innovative behavior.

Organizations' competitive positioning in the business landscape forces managers to face certain challenges. Opportunities, resource allocation, realized and potential capabilities require organization members to use strategic thinking to increase internal levels of absorptive capacity which market disruption conceivable. If organizational members can think strategically, in terms of how and when to disrupt their markets, they are then able to compete, sustain themselves, and endure. However, in studies conceptualizing strategic thinking, there has been a teasing out of the differences between strategic thinking and other cognitive theories, Capra (2002) focused on process thinking, March and Simon (1958) brought forth the development and use of cognitive mapping, Senge (1990) viewed thinking at the social systems level as process. Basadur, Runco and Vega (2000) discussed the role of creative thinking; Gross (2016) described leadership styles. While strategic thinking contains many elements of the cognitive processes, other modes of thinking do not use the same attributes of thinking that were presented in Liedtka's (1998) Five Pillars of Strategic Thinking, or in Norzailan, Yusaf, and Othman's (2016) strategic competencies (Gross, 2016). Nuntamanop, Kauranen, and Igel (2013) are correct in seeing a gap between strategic thinking and strategic management. That is not to say that managers do not use strategic thinking. Manager are actually more likely to act in line with strategic thinking but, as a matter of title and involvement in strategic 
alignment, they also have the resources to engage in the kind of strategic thinking that has a direct impact on business strategy.

In the literature, innovative behavior as an independent variable remains peripheral to the conversation on workplace behavior; not to mention its significant effects on workplace phenomena (Janssen, 2005). Smith and Tushman (2005) maintain that to survive and remain competitive, management must capitalize on short-term efficiency and insist on long-term innovative strategies. In such a system, divergent behavior is rooted in organizational strategy. Taking the psychological empowerment perspective, according to Pieterse, van Knippenberg, La Schippers and Stam (2010), individuals who are actively engaged in their work role have the motivation (Thomas \& Velthouse, 1990) and the self-efficacy to make choices, however, with the embedded focus of strategically thinking makes this proposition more sound, effectual and opportune in the organization of today. The crux of this assertion might assist in making innovative behavior a main antecedent of strategic thinking. Its effectiveness, frequency, and the individual deterministic attitude needed to think strategically.

Herein, the interplay is explored between behavior and thinking, were both intersect to form the manifestations of novel ideas and adaption of new tools, technologies to compete. With this line of thought, this intersection broadens the external purview so that competitors are acknowledged along with their potential capabilities, and internal potential capabilities can be defused and transmuted into realized capabilities (Cohen \& Levinthal, 1990) to meet market dynamics and competitive forces in real-time (Smith \& Tushman, 2005). Capitalizing on this premise, this research examines the interaction between innovative behavior as the independent variable and strategic thinking as the dependent variable. This interaction is subjected to hierarchical regression analysis, controlling for age, gender, years, and job title, as these control variables can cause spurious, unwanted effects on outcome variables (Kerlinger \& Lee, 2000). The research hypothesis is Innovative behavior has a positive impact on individual strategic thinking in an organizational context. This research is framed with a review of the literature, method, sample, instrumentation, analysis, results and discussion.

\section{REVIEW OF THE LITERATURE}

This review presents the literature in innovative behavior and strategic thinking. The literature assists in testing the hypothesis. The review is framed by a set of comprehensive views of innovative behavior and strategic thinking, primarily in the realm of organization. 


\section{A PANORAMIC VIEW OF INNOVATIVE BEHAVIOR}

Innovative behavior can be traced to Robertson's (1967) seminal work in which innovation was categorized as continuous, dynamically continuous and discontinuous. All three have a disruptive nature. Innovation is disruptive both in markets and within the organizational structure. Innovative behavior has four dimensions: idea exploration, idea generation, idea championing, and idea implementation (De Jong \& Den Hartog; Janssen, 2007; Scott \& Bruce, 1994; West \& Farr, 1989) .

Because of the landmark study by Scott and Bruce (1994), a distinction has been made between creativity, innovative behavior and their effects on organizational climate. Although both terms have a connotation of novelty, newness, and adaption, innovative behavior encompasses both the generation and implementation of ideas that exist on a continuum (Scott \& Bruce, 1994; West \& Farr, 1990). Janssen (2005) explains that innovative behavior can be realized in the workplace and has both perceived and real effects on individuals' ability to conceive and implement ideas, primarily because of the social arrangements in the workplace which establish appropriate behaviors among members, and innovative behavior are challenge to workplace norms (Ford, 1996; Janssen, 2005). On this note, Wu, Parker, and de Jong (2014) propose that in employees who engage in higher levels of work-related cognition, their activities are related to innovative behavior. $\mathrm{Wu}$, Parker and de Jog concluded that people who need high levels of work-related cognitive activity sought out novel ideas and tended to engage in complex and psychologically risky ideas. Their research included a sample of 179 employees between 22 and 64 years of age, with job tenure ranging from 2 to 40 years. They argued that employees with a high need for cognition in their work-task were more apt to develop stronger attitudes about the novelty of discovery, and be able to process ideas. Consistent with their hypothesis, employees with a strong need for cognition engage think than those employees with less, even when moderated by job pressure and deadlines.

Innovative behavior and its perceived influences on employee inputs can improve many of the efficiency and productivity indicators, some of which are increased organizational performance and a stronger relationship between employees and suppliers and or customers. In this sense, innovative behavior is a process of creative engagement (Drazin, Glynn, \& Kazajian, 1999). Whether the engagement produces novelty or not, it is the unrelenting innovative orientation of individuals involved in sense making. The outcomes have implications for the group, team, and organizational levels of analysis (Greenberg, 1990).

Taking a process-oriented approach to innovative behavior does not always fit neatly into organizational systems, based on the pivotal role and interaction with 
management objectives and the sociopolitical milieu in organizational systems. Janssen collected samples from 187 employees who were not managers, using hierarchical regression controlling for gender, age, and job tenure. The results suggest that employee-perceived influence and supervisor support of innovative behavior was positively related to innovative behavior. When employees believe they have impact on a process, they engage in behaviors that require creativity. In contrast, if employees perceive that their supervisor does not approve of idea generation and, they are more less likely to engage in innovation behavior. Therefore, the perception of management encourages or deters engagement in innovative behavior. In any attempt to use innovative behavior, employees' behaviors are reflected in observable, and qualifiable, perceptions of organizational norms and of management psychological and resource support.

Learning organizations outperform those that do not embrace the acquisition of new knowledge, and that do not use knowledge to develop and cultivate tools that would confer an advantage in process and product/service development. The core elements of the learning organization are leadership, organizational support, encouragement, employee development, all of which consists of two dimensions: people and structure (Park, Song, Yoon \& Kim, 2014) Park et al. (2014) see connections between learning organizations and innovative behavior in an absorptive capacity (Cohen \& Levin, 1990) perspective; this is where knowledge filters through organizational processes based on structural acquisition, assimilation to exploitation and commercialization of the acquired knowledge. Park et al. contend that work engagement mediates the relationship between learning organizations and innovative behavior.

If organizational learning is to permeate the organization ecosystem, it needs a climate conducive to autonomy, collaboration, and support (Ren \& Zhang, 2015). When the organizational climate is strong, employees are committed to the innovative process, which involves learning and applying new knowledge. The organizational climate is critical for the socio-political and psychological effects of supporting innovative behavior in the workplace. Ren and Zhang (2015) found a significant correlation between organizational climate and innovation on employee innovative behavior; job challenges and stressors did not moderate the relationship between strategic thinking and innovative behavior to make a large enough effect.

H1: Innovative behavior has a positive impact on individual strategic thinking in an organizational context.

\section{A LATITUDINAL VIEW OF STRATEGIC THINKING}


Pisapia, Ellington, Toussaint, and Morris (2011) present three dimensions of strategic thinking: reframing, reflection, and systems thinking. Reframing is the ability to think through multiple lens even in the midst of chaos. One must be able to change perceptions based on situations and changing simultaneous perspectives and by implementing novel ideas and reflection, examination, and reexamination of both success and failures in a way that one can view assumptions in relation to rules, policies, and procedures. Pisapia et al. (2011) say that strategic thinking "requires the ability to recognize patterns, examine new possibilities, dealing with large chunks of information, and the ability to pull pieces together into a big picture" (p. 2).

Bonn (2005) postulates that strategic thinking solves problems that are inherent in strategy, where one culls both rational and convergent thought processes. With technological advances in the workplace and the competitive forces in the dynamic business landscape, management and employees alike must possess strategic thinking skills and competencies. Regardless of the cognitive and environmental contextual factors discussed in the literature, it is axiomatic that in dynamic industries the use of strategic thinkers remains imperative. Those with an unconstrained view of strategic thinking (Bonn, 2005; Heracleous, 1998; Liedtka, 1998), approve of its use in creative, analytical, and visionary capabilities that lay outside the scope of traditional boundaries of the social structure. However, there is a constrained view of strategic thinking (Keeney, 1994) where values are placed in lockstep with action derived from principled and conventional preemptive identification as a basis of decision-making.

Organizational leaders are able to use foresight to prepare for any unforeseen events. When a strategy fails unexpectedly, strategic thinking can support the need for realignment (Self, Self, Matuszek \& Schraeder, 2015). If derailment is the result of employee and management inertia, misdirection or lack of leadership, this reverberates throughout the organization, including management.

Jelenc, Pisapia and Ivancic (2016) found that strategic thinking is positively linked with entrepreneurial attitude orientation; there was a direct link with, innovation, one of the domains of entrepreneurial attitude orientation. Strategic thinking has been documented by many theorist (Allio, 2012; Gross, 2016; Haycock, 2012; Nuntamanop, Kauranen, \& Igel, 2013; Pisapia, Ellington, Toussaint, \& Morris, 2011 ), and was found to be significantly and positively related to transformational and transactional leadership styles (Gross, 2016). Of the three leadership styles, both transformational and transactional were significant and positively related with strategic thinking; laissez-faire was not.

Strategic thinking must be viewed in terms of its effects on individuals' ability within the ecosystem and on the paradigm of management and leadership (Gross, 
2016). However, at the organizational level, leaders' mind maps and models need to be transformed, redefined, and reinterpreted to transmute innovative ideas, attitudes, and behaviors linked to increased strategic thinking.

Managers with a parochial view of strategy might find themselves working under an old paradigm is incompatible with the new paradigm. Many contextual factors are tied to hypercompetitive markets, fast developments, and knowledge sharing through open innovation methodologies. This causes an unconstrained view of strategic thinking, to make critical decisions and adjustments in real time. With the consistent practice of strategic thinking, it is easy to believe that the more an action is repeated, the better one gets at it. Consistent practice and exposure to various tasks and projects would accumulate into a reservoir from which one could draw when it was time to think strategically. Dragoni, Sue Oh, Vankatwyk and Tesluk (2011) sampled 700 executives to test whether work experience accumulation was related to strategic thinking. They used hierarchical regression analysis, controlled for gender, ethnicity, and work experience, and found that accumulated work experience did impact with strategic thinking, along with cognitive ability, although this finding does not aid in causation.

Goldman (2012) provides leadership practices to enhance organizational members' strategic thinking. Since strategic thinking is embedded in organizational culture, organizational leadership is paramount in its cultivation (Gross, 2016). Goldman and Casey (2010) provide three conceptualizations of strategic thinking in relation to organizational culture:

1. Strategic thinking is essential to strategy development

2. Strategic thinking is a mental/cognitive process

3. Strategic thinking involves perspectives and social activities

Goldman's analysis suggests that organizational leaders have to create more cognitive and social interaction through leadership skills to enhance strategic thinking performance. The leadership practices of the executive sample respondents in this study were either heavy or light. Leadership practices that increased strategic thinking are reacting, structuring, and developing. These leadership practices are relevant when managers discuss and review external changes with organizational members and the way in which those changes might affect their current or future situations; the need to allocate resources and alternate strategy planning roles; recognize individual/team strategic thinkers; and formulate the organizational policies and procedures that contribute to resolving crises. 


\section{METHODS}

A non-experimental, cross-sectional research design was used to gather data from respondents, analyze results, and infer meaning (Kerlinger \& Lee, 2000). An effective research design should maximize the variance of the variables being tested, minimize error, and control unwanted variables that could influence the outcomes (Kerlinger \& Lee, 2000). A cross-sectional design was used because it is economically viable and is responsive to quick turnarounds (Kerlinger \& Lee, 2000).

Two survey instruments were used to generalize a sample to a population and to measure attitudes, behaviors, and sentiments (Creswell, 2009). Sample response data were gathered from respondents from managers and nonmanagers, then tabulated and analyzed using SPSS software. Hierarchical regression analysis was used to make sense of these data. With a total of four independent variables, three of which were control variables (i.e. gender, age, and years of experience) that maximizes the effect of the independent variable. Kerlinger and Lee recommend that to control for extraneous variables, it is best to build them into the design as independent variables. The proceeding sections provide sample demographics, instrumentation, results and discussion, conclusion and limitations.

\section{SAMPLES}

Self-administered questionnaires were distributed randomly to managers and their subordinates. The samples were collected for 6-7 months, throughout the southeastern United States. Convenience sampling was used as many sample respondents formed natural groups based on their title, work location, and place in the organization (Creswell, 2009). Employees varied in age, gender, education, experience, and administrative titles.

The breakdown of industries is as follows: $40 \%$ sales, $20 \%$ services, and $40 \%$ technology/manufacturing industries. In terms of the gender, $63 \%$ male and $37 \%$ female. Sixty five percent (65\%) of the employees were 30 and over were $35 \%$ of the population of respondents were 30 and younger. There were 100 usable samples; 155 attempts were made, receiving a useable total percentage of $65 \%$. Hair, Black and Babin (2010) suggests a sample size of 15-20 and should not fall below a ratio of 5:1. Since this research includes four independent variables (innovative behavior, age, gender, years on job) and one dependent variable (strategic thinking), this recommendation applies. 


\section{INSTRUMENTS}

Pisapia, Reyes-Guerra and Coukos-Semmel's (2005) Strategic Thinking scale (STQ) was used. The scale has a five-point Likert scale $(1=$ almost never uses to $5=$ almost always uses); yielded a Cronbach's alpha of .91, has 25 items, and has three subscales: systems thinking, reflecting, and reframing. Innovative behavior was measured using the instrument created by Scott and Bruce (1994). Its dimensions are idea exploration, idea generation, idea championing, and idea implementation. It is a six-item scale, with a Cronbach's alpha of 0.92 , reliability of 0.89 , and a 5-point Likert scale (from $1=$ not at all to $5=$ to an exceptional degree).

\section{ANALYSIS}

Table 1 Descriptive Statistics

\begin{tabular}{lllll}
\hline & $N$ & Mean & Std. Deviation & Variance \\
\hline Strategic Thinking & 100 & 3.8 & .83 & .69 \\
Innovative Behavior & 100 & 3.2 & .86 & .74 \\
Age & 100 & 1.3 & .47 & .23 \\
Gender & 100 & 1.3 & .48 & .23 \\
Years on Job & 100 & 1.7 & .44 & .19 \\
Valid N (listwise) & 100 & & & \\
\hline
\end{tabular}

Table 2 Correlations between Variables

\begin{tabular}{|c|c|c|c|c|c|c|c|}
\hline & & & 1 & 2 & 3 & 4 & 5 \\
\hline \multirow{9}{*}{ Spearman's rho } & Strategic & Correlation & 1.0 & & & & \\
\hline & Innovative & Correlation & $.27^{* *}$ & & & & \\
\hline & Behavior & Sig. (2-tailed) & $.00 *$ & - & & & \\
\hline & \multirow{2}{*}{ Age } & Correlation & .14 & .2 & & & \\
\hline & & Sig. (2-tailed) & .15 & .04 & - & & \\
\hline & \multirow{2}{*}{ Gender } & Correlation & -.03 & .00 & .05 & & \\
\hline & & Sig. (2-tailed) & .80 & .99 & .65 & - & \\
\hline & \multirow{2}{*}{ Years on Job } & Correlation & -.13 & -.0 & -.09 & .12 & \\
\hline & & Sig. (2-tailed) & .22 & .44 & .37 & .22 & \\
\hline
\end{tabular}

**. Correlation is significant at the 0.01 level (2-tailed).

*. Correlation is significant at the 0.05 level (2-tailed). 
Table 3 Model Summary

\begin{tabular}{|c|c|c|c|c|c|c|c|c|c|}
\hline \multirow[b]{2}{*}{ Model } & \multirow[b]{2}{*}{$\mathrm{R}$} & \multirow[b]{2}{*}{ R Square } & \multicolumn{7}{|c|}{ Change Statistics } \\
\hline & & & $\begin{array}{c}\text { Adjusted R } \\
\text { Square }\end{array}$ & $\begin{array}{l}\text { Std. Error of } \\
\text { the Estimate }\end{array}$ & $\begin{array}{l}\text { R Square } \\
\text { Change }\end{array}$ & F Change & df1 & $\mathrm{df} 2$ & $\begin{array}{c}\text { Sig. F } \\
\text { Change }\end{array}$ \\
\hline 1 & $.20^{\mathrm{a}}$ & .04 & .01 & .83 & .04 & 1.3 & 3 & 96 & .26 \\
\hline 2 & $.31^{\mathrm{b}}$ & .09 & .05 & .81 & .05 & 5.6 & 1 & 95 & .02 \\
\hline
\end{tabular}

a. Predictors: (Constant), Years on Job, Age, Gender

b. Predictors: (Constant), Years on Job, Age, Gender, Innovative Behavior

Table 4 ANOVA $^{\mathrm{a}}$

\begin{tabular}{llccccc}
\hline Model & & Sum of Squares & df & Mean Square & F & Sig. \\
1 & Regression & 2.7 & 3 & .93 & 1.35 & $.26^{\mathrm{b}}$ \\
& Residual & 65.9 & 96 & .69 & & \\
& Total & 68.7 & 99 & & & \\
\cline { 2 - 7 } & Regression & 6.4 & 4 & 1.6 & 2.45 & $\mathbf{. 0 5}^{\mathrm{c}}$ \\
& Residual & 62.3 & 95 & .63 & & \\
& Total & 68.7 & 99 & & & \\
\hline
\end{tabular}

a. Dependent Variable: Strategic Thinking

b. Predictors: (Constant), Years on Job, Age, Gender

c. Predictors: (Constant), Years on Job, Age, Gender, Innovative Behavior

Table 5 Regression Coefficient

\begin{tabular}{llccc}
\hline & & Model 1 & Model 2 & Sig \\
\hline Step 1 & (Control Variables) & & & \\
& Age & .15 & .09 & .14 \\
& Gender & -.03 & -.03 & .78 \\
& Years on job & -.12 & -.10 & .25 \\
Step 2 & & & \\
& Age & & .09 & .35 \\
& Gender & & -.03 & .78 \\
& Years on job & & -.10 & .29 \\
& Innovative behavior & & $.24 *$ & .02 \\
& $R^{2}$ & .04 & .09 & \\
& $F$ & 1.3 & 5.6 & \\
& df & $(3,96)$ & $(1,95)$ & \\
$R^{2}$ Change & .04 & $.05 *$ & \\
\hline
\end{tabular}

$*_{p}<.05$. 


\section{RESULTS AND DISCUSSION}

Table 1 reports the demographic statistics pertaining to the employee respondent samples used to test the study hypothesis; showing also each variable mean, standard deviation, and variance. Table 2 shows the correlations between variables. Innovative behavior and strategic thinking are shown to be correlated, as are age and innovative behavior. Table 3 reports the model summary based on the regression models, and table 4 reports the ANOVA output which additionally supports the significance of the regression models 1 and 2.

As shown in table 2, the control variance $\left(\mathrm{R}^{2}\right)$ on the first model was $4.3 \%$. This figure increased to $9.3 \%$ in the second model which encompasses both the independent and control variables. The change in $\mathrm{R}^{2}$ shows that the independent variable, innovative behavior, accounts for $5.3 \%$ in the dependent variable: strategic thinking. The change statistics, $\mathrm{F}(3.96)=5.6, \mathrm{P}<.05)$, and the ANOVA output, on table 4 model 2 , is significant showing, $\mathrm{F}(4,95)=2.5, \mathrm{P}<.05)$. Table 5 supports the research hypothesis, where the coefficients show a positive and significant $(\beta=.24$, $p<.05)$ impact of innovative behavior on strategic thinking in an organizational context. These variables (innovative behavior and strategic thinking) have not yet been tested quantitatively. This juncture opens new theoretical windows that can now be explored by further inquiries.

Innovative behavior and its dimensions can be effective if there is a sustainable culture within the organizational structure, and management has adopted a systems view (Liedtka, 1998), then organizational members are able to apply and engage innovative behavior to work-related task. On the same note, thinking-in-time and hypothesis driven skills are both linked with the dimensions of innovative behavior (e.g., idea generation, idea implementation, idea champion, and idea exploration). To think-in-time, one must be able to generate and concretize ideas; a person who is hypothesis-driven has the cognitive ability to explore and test ideas in real time. The finding in this research align well with the outcomes from Carmeli, Meitar and Weisberg's (2006) study in which innovative behavior was positively linked with constructive thought strategies and individual behavior and individuals' intrinsic abilities.

Carmeli et al. showed individuals' predictive patterns of innovative behavior and engagement is viewed and perceived based on self-assertion and self-leadership skills, either needed or possessed to establish stronger innovative behavior in-job roles. Martins and Terblanche's (2003) cultural perspective seems consistent with this finding. They surmised that culture is the core of innovation and strategy, and there needs to be greater emphasis on quantifying the interaction among these variables. 


\section{CONCLUSION}

This research brings a new theoretical development to the innovative behavior and strategic thinking literature, by suggesting a significant and positive impact of innovative behavior on individual strategic thinking. Quantitatively, this study should be used as a proxy and baseline for future developments linking other organizational and managerial constructs to strategy thinking and making, building, and alignment. Now that this study has made the link, its practical implications are warranted. Organizational leaders should enhance the connections between innovative behavior with the conceptualization of strategic thinking and the implementation of ideas to encourage active strategic thinking. The implementation of new and useful ideas fosters a change of perspective, reframing abilities that increases one's view of systems. The notion that idea exploration, generation, implementation, and championing preceded and benefits strategic thinking is critical. Although this study is parochial in many respects, managers can draw important implications that concretize the full spectrum of idea exploration and effects on employee strategic thinking, where the psychologic effects of this behavior are buttressed by the employees' perception of management supportiveness. Formulating ideas, devising strategy, and realigning tactics can be onerous in real time; however, this development views strategic engagement and planning and value of idea generation fostered by nonmanagers and managers alike. Strategic thinking considers multiple frames and strategies, and is antithetical to the constrained view.

\section{REFERENCES}

Allio, R. J. (2012). Leaders and leadership-many theories, but what advice is reliable? Strategy \& Leadership, 41(1), 4-14. https://doi.org/10.1108/10878571311290016 Basadur, M., Runco, M. A., \& Vega, (2000). Understanding how creative thinking skills, attitudes and behaviors work together: A causal process model. The Journal of Creative Behavior,34(2), 77-100. https://doi.org/10.1002/j.21626057.2000.tb01203.x

Bonn, I. (2005). Improving strategic thinking: a multilevel approach. Leadership \& Organization Development Journal,26(5), 336-354. https://doi.org/10.1108/01437730510607844

Capra, F. (2002). The Hidden Connections: A Science for Sustainable Living Harper Collins. New York, NY.

Carmeli, A., Meitar, R., \& Weisberg, J. (2006). Self-leadership skills and innovative behavior at work. International Journal of Manpower, 27(1), 75-90. https://doi.org/10.1108/01437720610652853 
Cohen, W. M., \& Levinthal, D. A. (1990). Absorptive capacity: A new perspective on learning and innovation. Administrative science quarterly, 128-152. https://doi.org/10.1016/B978-0-7506-7223-8.50005-8

Creswell, J. (2009).Research design: Qualitative, quantitative, and mixed methods approaches. Sage Publicaions: Thousand Oaks, CA.

De Jong, J. P., \& Den Hartog, D. N. (2007). How leaders influence employees' innovative behaviour. European Journal of innovation management, 10(1), 41-64. https://doi.org/10.1108/14601060710720546

Dougherty, D., \& Heller, T. (1994). The illegitimacy of successful product innovation in established firms. Organization Science, 5(2), 200-218. https://doi.org/10.1287/orsc.5.2.200

Dragoni, L., Oh, I. S., Vankatwyk, P., \& Tesluk, P. E. (2011). Developing executive leaders: The relative contribution of cognitive ability, personality, and the accumulation of work experience in predicting strategic thinking competency. Personnel psychology, 64(4), 829-864. https://doi.org/10.1111/j.17446570.2011.01229.x

Drazin, R., Glynn, M. A., \& Kazanjian, R. K. (1999). Multilevel theorizing about creativity in organizations: A sensemaking perspective. Academy of Management Review, 24(2), 286-307. https://doi.org/10.5465/amr.1999.1893937

Flora Hung, C. J. (2004). Cultural influence on relationship cultivation strategies: Multinational companies in China. Journal of Communication Management, 8(3), 264-281. https://doi.org/10.1108/13632540410807682

Ford, C. M. (1996). A theory of individual creative action in multiple social domains. Academy of Management review, 21(4), 1112-1142. https://doi.org/10.5465/amr.1996.9704071865

Goldman, E. F., \& Casey, A. (2010). Building a culture that encourages strategic thinking. Journal of Leadership \& Organizational Studies, 17(2), 119-128. https://doi.org/10.1177/1548051810369677

Goldman, E. F. (2012). Leadership practices that encourage strategic thinking. Journal of Strategy and Management, 5(1), 25-40. https://doi.org/10.1108/17554251211200437

Greenberg, J. (1990). Organizational justice: Yesterday, today, and tomorrow. Journal of management,16(2), 399-432. https://doi.org/10.1177/014920639001600208

Gross, R. (2016). Towards an Understanding of the Relationship between Leadership Styles and Strategic Thinking: A Small and Medium Enterprise Perspective. Journal of Business Studies Quarterly, 8(2), 22-39. 
Hair, J. F., Black, WC, Babin, BJ, \& Anderson, RE (2010). Multivariate data analysis, 7. Pearson Education Upper Saddle. New Jersey, NJ.

Haycock, K. (2012). Strategic Thinking and Leadership. Library leadership \& management, 26(3/4).

Heracleous, L. (1998). Strategic Thinking or Strategic Planning? Long range planning, 31(3), 481-487. https://doi.org/10.1016/S0024-6301(98)80015-0

Janssen, O. (2005). The joint impact of perceived influence and supervisor supportiveness on employee innovative behaviour. Journal of occupational and organizational psychology, $78(4)$ 573-579. https://doi.org/10.1348/096317905X25823

Jelenc, Lara, John Pisapia, and Valentina Ivančić. (2016) Strategic Thinking Capability and Entrepreneurial Attitude Orientation: Links and Relations. Retrieved from: https://www.researchgate.net/publication/303920645_Strategic_Thinking_Capab ility_and_Entrepreneurial_Attitude_Orientation_Links_and_Relations

Keeney, R. L. (1994). Creativity in decision making with value-focused thinking. Sloan Management Review, 35(4), 33.

Kerlinger, F. N., \& Lee, H. B. (2000). Survey research. Foundations of behavioral Research, 599-619.

Liedtka, J. M. (1998). Strategic thinking: can it be taught? Long range planning, 31(1), 120-129. https://doi.org/10.1016/S0024-6301(97)00098-8

March, J. G., \& Simon, H. A. (1958). Organizations. Oxford, England: Wiley.

Martins, E. C., \& Terblanche, F. (2003). Building organisational culture that stimulates creativity and innovation. European Journal of Innovation Management, 6(1), 64-74. https://doi.org/10.1108/14601060310456337

Norzailan, Z., Yusof, S. M., \& Othman, R. (2016). Developing Strategic Leadership Competencies. Journal of Advanced Management Science Vol, 4(1).

Nuntamanop, P., Kauranen, I., \& Igel, B. (2013). A new model of strategic thinking competency. Journal of Strategy and Management,6(3), 242-264. https://doi.org/10.1108/JSMA-10-2012-0052

Park, Y. K., Song, J. H., Yoon, S. W., \& Kim, J. (2014). Learning organization and innovative behavior: The mediating effect of work engagement. European Journal of Training and Development,38(1/2), 75-94. https://doi.org/10.1108/EJTD-04-2013-0040

Pieterse, A. N., Van Knippenberg, D., Schippers, M., \& Stam, D. (2010). Transformational and transactional leadership and innovative behavior: The 
moderating role of psychological empowerment. Journal of Organizational Behavior, 31(4), 609-623. https://doi.org/10.1002/job.650

Pisapia, J., Ellington, L., Toussaint, G., \& Morris, J. D. (2011). Strategic thinking skills: Validation and confirmation of constructs. Retrieved from: http://fau.academia.edu/JohnPisapia/Papers/776012/Strategic_Thinking_Skills_V alidation_and_Confirmation_of_Constructs

Pisapia, J., Reyes-Guerra, D., \& Coukos-Semmel, E. (2005). Developing the leader's strategic mindset: Establishing the measures. Leadership Review, 5(1), 41-68

Ren, F., \& Zhang, J. (2015). Job stressors, organizational innovation climate, and employees' innovative behavior. Creativity Research Journal, 27(1), 16-23. https://doi.org/10.1080/10400419.2015.992659

Robertson, T. S. (1967). The process of innovation and the diffusion of innovation. The Journal of Marketing, 31(1), 14-19.

Scott, S. G., \& Bruce, R. A. (1994). Determinants of innovative behavior: A path model of individual innovation in the workplace.Academy of management journal, 37(3), 580-607. https://doi.org/10.5465/256701

Self, D. R., Self, T., Matuszek, T., \& Schraeder, M. (2015). Improving organizational alignment by enhancing strategic thinking. Development and Learning in Organizations: An International Journal, 29(1), 11-14. https://doi.org/10.1108/DLO-08-2013-0053

Senge, P.M. (1990), The Fifth Discipline, Doubleday/Currency, New York

Smith, W. K., \& Tushman, M. L. (2005). Managing strategic contradictions: A top management model for managing innovation streams. Organization science, 16(5), 522-536. https://doi.org/10.1287/orsc.1050.0134

Thomas, K. W., \& Velthouse, B. A. (1990). Cognitive elements of empowerment: An "interpretive" model of intrinsic task motivation. Academy of management review, 15(4), 666-681. https://doi.org/10.5465/amr.1990.4310926

West, M. A., \& Farr, J. L. (1989). Innovation at work: Psychological perspectives. Social behavior, 4(1),15-30.

West, M. A., \& Farr, J. L. (1990). Innovation and creativity at work: Psychological and Organizational Strategjes. NY: John Wiley \& Sons, 265-267.

Wu, C. H., Parker, S. K., \& De Jong, J. P. (2014). Need for cognition as an antecedent of individual innovation behavior. Journal of Management, 40(6), 1511-1534. https://doi.org/10.1177/0149206311429862 
